Josep M. Auge*, Cristina Rodriguez, Oihana Espanyol, Liseth Rivero, Silvia Sandalinas, Jaume Grau, Wladimiro Jimenez and Antoni Castells

\title{
An evaluation of the SENTiFIT 270 analyser for quantitation of faecal haemoglobin in the investigation of patients with suspected colorectal cancer
}

https://doi.org/10.1515/cclm-2017-0605

Received July 11, 2017; accepted October 9, 2017; previously published online November 18, 2017

\section{Abstract}

Background: An evaluation of SENTiFIT ${ }^{\circledR} 270$ (Sentinel Diagnostics, Italy; Sysmex, Spain) analyser for the quantitation of faecal haemoglobin (f-Hb) was performed.

Methods: The analytical imprecision, linearity, carry over and $\mathrm{f}-\mathrm{Hb}$ stability were determined. Evaluation of the diagnostic accuracy was performed on 487 patients.

Results: Within-run and between-run imprecision ranged $1.7 \%-5.1 \%$ and $3.8 \%-6.2 \%$, respectively. Linearity studies revealed a mean recovery of $101.1 \%$ (standard deviation, $6.7 \%$ ) for all dilutions. No carry over was detected below $7650 \mu \mathrm{g} \mathrm{Hb} / \mathrm{g}$ faeces. Decay of $\mathrm{f}-\mathrm{Hb}$ in refrigerated samples ranged $0.2 \%-0.5 \%$ per day. $\mathrm{f}-\mathrm{Hb}$ in patients with advanced colorectal neoplasia (ACRN) (colorectal cancer [CRC] plus advanced adenoma [AA]) were significantly higher than from those with a normal colonoscopy. Sensitivity for ACRN at f-Hb cutoffs from 10 to $60 \mu \mathrm{g} \mathrm{Hb} / \mathrm{g}$ faeces ranged from $28.9 \%$ (95\% confidence interval [CI], 21.7\%-37.2\%) to $46.5 \%$ (95\% CI, 38.1\%-55\%), the specificity ranged from $85 \%$ (95\% CI, $82.3 \%-87.3 \%$ ) to $93.2 \%$ (95\% CI, $91.2 \%-$ 94.8\%), positive predictive values for detecting CRC and AA ranged from $11.6 \%$ (95\% CI, 7.6\%-17.2\%) to 20.6\% (95\% CI, $13.3 \%-30.3 \%)$ and from $34.7 \%$ (95\% CI, $28.1 \%-42 \%)$ to $42.3 \%$ (95\% CI, 32.4\%-52.7\%), respectively, and the negative predictive value for ACRN ranged from 90.2\% (95\% CI, 87.9\%-92.2\%) to $88.4 \%$ (95\% CI, 86\%-90.4\%). Using two samples per patient sensitivity increased with a slight decrease in specificity.

${ }^{\star}$ Corresponding author: Josep M. Auge, Biochemistry and Molecular Genetics Department, Biomedical Diagnostic Center, Hospital Clinic, C/Villarroel 170, 08036 Barcelona, Spain, E-mail: jmauge@clinic.cat Cristina Rodriguez, Liseth Rivero and Antoni Castells:

Gastroenterology Department, Hospital Clinic, University of Barcelona, Barcelona, Spain; and IDIBAPS, CIBERehd, Barcelona, Spain Oihana Espanyol, Silvia Sandalinas and Wladimiro Jimenez: Biochemistry and Molecular Genetics Department, Biomedical Diagnostic Center, Hospital Clinic, Barcelona, Spain Jaume Grau: Unit of Evaluation, Support and Prevention, Hospital Clinic, Barcelona, Spain
Conclusions: The analytical and clinical performances of SENTiFIT assay demonstrate a specific and accurate test for detecting ACRN in symptomatic patients and those undergoing surveillance.

Keywords: adenoma; analyser evaluation; colorectal cancer; faecal haemoglobin; faecal immunochemical test.

\section{Introduction}

The faecal immunochemical test (FIT) for faecal haemoglobin (f-Hb) has been widely adopted in screening programmes [1-4], and its usefulness for assessing patients with lower gastrointestinal symptoms has begun to be explored [5-11].

The FIT allows for quantitative measurement of $\mathrm{f}-\mathrm{Hb}$ concentration, which makes it possible to select the optimal cutoff $[2,12-16]$ for each situation. Quantitative FIT generally uses automated analysis to determine $\mathrm{f}-\mathrm{Hb}$ concentration, which allows high-throughput testing, improves reproducibility, and removes bias in the interpretation of the results [17].

In the last few years, the number of analysers, reagents and specimen collection devices available on the market has increased. Currently, several FIT manufacturers offer analytical systems that differ in terms of, for instance, the volume of haemoglobin-stabilising buffer in the specimen collection devices and the sample mass used for the test [18]. Initiatives to standardise methods and reporting units have been undertaken [19-22]. Nevertheless, each brand of FIT performs differently [23]. For this reason, it is advisable to evaluate the features of FIT reagents, analysers and specimen collection devices prior to use.

The main aim of this study was to assess the analytical and diagnostic capabilities of SENTiFIT ${ }^{\circledR} 270$ using SENTiFIT $^{\circledR}$-FOB Gold ${ }^{\circledR}$ latex reagent and SENTiFIT ${ }^{\circledR}$ pierceTube (Sentinel Diagnostics, Italy; Sysmex, Spain). As a secondary aim, we studied the diagnostic yield for advanced colorectal neoplasia (ACRN) of $\mathrm{f}-\mathrm{Hb}$ concentration using the first result of two samples vs. the mean and the higher concentration of two samples. 


\section{Materials and methods}

\section{Patients}

The study analysed 487 consecutive patients ( $48.8 \%$ males) whose average age was 62 years (range: 22-94 years), who attended the Hospital Clinic of Barcelona from June to October 2015 for colonoscopy to assess lower gastrointestinal symptoms (264 patients) or for surveillance of colonic polyps (223 patients).

Patients were asked to begin collecting faecal samples for the FIT 5 days before their colonoscopy to ensure that two samples were collected before bowel preparation commenced. No dietary restrictions were imposed. Medication such as aspirin and non-steroidal anti-inflammatory drugs was discontinued 1 week before preparation for colonoscopy. The study was approved by the Hospital Clinic's Ethics Committee (HCB/2015/0388), and all patients provided written informed consent. All participants received an explanation of the tests and written instructions for the FIT either face to face or over the telephone. Patients were asked to prepare faecal samples from two consecutive bowel motions using the collection kit provided by the manufacturer.

\section{Samples}

Three sample sources were used: (1) samples collected by the patients, (2) stabilising buffer spiked with human capillary blood and (3) control material provided by the manufacturer. To collect a sample, the patient unscrews the green cap with the attached sample collection stick and inserts it in four different spots in the faeces, scratching the surface cross-wise. The grooves of the stick must be fully covered in faeces. Then, the patient replaces the stick into the specimen collection device and screws it shut. The collection device is designed to collect $10 \mathrm{mg}$ of freshly passed faeces with a serrated stick in a standard volume of haemoglobin-stabilising buffer $(1.7 \mathrm{~mL})$. Samples were stored in double-zipper bags at $4{ }^{\circ} \mathrm{C}$ until analysis was performed (within a maximum of 5 days).

\section{Analyser}

SENTiFIT $^{\circledast} 270$ was used for quantitation of the $\mathrm{f}-\mathrm{Hb}$ (Sentinel Diagnostics, distributed in Spain by Sysmex España, S.L.U.). This is a desktop instrument based on immunoturbidimetry that can perform up to 270 tests per hour. It includes SENTiFIT ${ }^{\circledast}$ FOB Gold $^{\circledast}$ latex reagent, FOB Gold ${ }^{\circledR}$ Screen Diluent, washing and fluid-disposal bottles, and it requires access to a standard power supply. Forty faecal samples prepared by patients using the SENTiFIT ${ }^{\circledR}$ pierceTube were loaded into the sample carousel. The instrument automatically mixes the faecal buffer solution with a latex-antihuman haemoglobin antibody reagent. The latex particles react with faeces samples containing human haemoglobin. The agglutination of the latex particles is proportional to the concentration of haemoglobin in the sample. By applying a conversion factor of 0.17 , the concentration of haemoglobin in the buffer (ng $\mathrm{Hb} / \mathrm{mL}$ buffer) can be used to determine the concentration of haemoglobin in faeces ( $\mu \mathrm{g} \mathrm{Hb} / \mathrm{g}$ faeces). The measurement range is from 2 to $129 \mu \mathrm{g} \mathrm{Hb} / \mathrm{g}$ faeces, the highest calibration concentration. All events were performed in accordance with the maintenance tasks, calibration methods and quality controls recommended by the manufacturer. The analyses were performed by a trained clinical laboratory technician. The laboratory has a total quality management system and is certified to ISO 9001:2015 standards by AENOR, Asociación Española de Normalización y Certificación (Spain).

\section{Protocol design}

An evaluation protocol was designed that included a training period and an analytical evaluation phase in which imprecision, the linearity of dilution, the carry over and $\mathrm{f}-\mathrm{Hb}$ stability were examined. A clinical evaluation was performed to compare the $\mathrm{f}-\mathrm{Hb}$ concentrations for different colonoscopy findings, including receiver operating characteristic (ROC) curves. Adenomas measuring $10 \mathrm{~mm}$ or more in diameter with villous architecture, high-grade dysplasia or intramucosal carcinoma were classified as advanced adenoma (AA). Invasive colorectal cancer (CRC) was considered to be present when malignant cells were observed beyond the muscularis mucosae. ACRN was defined as AA or invasive CRC. The sensitivity and specificity for CRC, AA and ACRN at different $\mathrm{f}-\mathrm{Hb}$ cutoffs using all collected samples were assessed as well as the diagnostic yield at different cutoffs, achieved using the first $\mathrm{f}-\mathrm{Hb}$ concentration of two samples and the mean and the higher $\mathrm{f}-\mathrm{Hb}$ concentration of two samples.

Analytical imprecision: Six samples (two controls, two haemoglobin-spiked buffers and two $\mathrm{f}-\mathrm{Hb}$ patient samples) were quantified and repeatedly examined 19 times in 1 day, and two controls were examined every day for at least 20 days. The mean, the standard deviation (SD) and the coefficient of variation (CV) of each sample were calculated.

Linearity: The highest concentration standard ( $129 \mu \mathrm{g} \mathrm{Hb} / \mathrm{g}$ faeces) was diluted with the appropriate buffer diluent to obtain a minimum of five dilutions within the dynamic range of the assay. Dilutions were prepared using calibrated pipettes. Recovery was calculated according to the highest measured concentration.

Sample carry over: carry over was determined using two human blood-spiked buffer samples: a sample with a low test result close to the relevant decision cutoff $(\sim 20 \mu \mathrm{g} \mathrm{Hb} / \mathrm{g}$ faeces) and a sample with a very high haemoglobin concentration $(7650 \mu \mathrm{g} \mathrm{Hb} / \mathrm{g}$ faeces). The samples were divided into 10 low aliquots (L) and 5 high aliquots $(\mathrm{H})$. The aliquots were loaded into the analyser in the following order: $\mathrm{L}$, L, L, L, L, H, L, H, L, H, L, H, L, H, L. The difference between the mean of the low measurements after a high measurement and the mean of the low measurements after a low measurement is equal to the carryover. The maximum deviation was defined as twice the SD of the first five low measurements [24].

Test stability: Thirteen of the patients' samples ranging from 12 to $1001 \mu \mathrm{g} \mathrm{Hb} / \mathrm{g}$ faeces were aliquoted into single-use Eppendorf tubes to avoid contamination. They were stored at room temperature and then refrigerated and periodically analysed over 20 days. Their cumulative change compared with the initial measurement was reported as a ratio.

Endoscopy: Colonoscopies were performed without knowledge of the FIT results, and only those reaching the caecum or an obstructing 
carcinoma, if present, were selected. All lesions were categorised, and if colorectal polyps were detected, the polyp sites were recorded and polypectomy was performed. Polyps were examined histologically, and the size and type of each polyp were recorded according to the guidelines published by the European Society of Gastrointestinal Endoscopy [25]. The location and histology of carcinomas were also recorded. Polyps were categorised as either AA or non-advanced adenoma (NAA). Tumour staging was performed according to the TNM classification system used by the Union for International Cancer Control (UICC) [26]. Patients were classified according to the most advanced lesion present.

\section{Statistical analysis}

A logarithmic transformation was performed to obtain a graphic representation of $\mathrm{f}-\mathrm{Hb}$ concentrations. The Mann-Whitney U-test was used to analyse differences between groups' haemoglobin concentrations. An ROC curve for the FIT was drawn to determine the $\mathrm{f}-\mathrm{Hb}$ cutoffs. Sensitivity, specificity and their $95 \%$ confidence interval (CI) were determined with the following two equations:

$$
\begin{aligned}
\text { Sensitivity }(\mathrm{S})= & \text { True positive }(\mathrm{TP}) /(\text { True positive }[\mathrm{TP}] \\
& + \text { False negative }[\mathrm{FN}]) \\
\text { Specificity }(\mathrm{SP})= & \text { True negatives }(\mathrm{TN}) /(\text { True negatives }[\mathrm{TN}] \\
& + \text { False positives }[\mathrm{FP}])
\end{aligned}
$$

The positive predictive value (PPV), negative predictive value (NPV) and their 95\% CI for ACRN, CRC and AA at different $\mathrm{f}-\mathrm{Hb}$ concentrations were also calculated. The ROC curves for one and two tests were compared using the Delong method, and differences in sensitivity and specificity were calculated using one and two samples at the same cutoff. We determined the Pearson correlation coefficients of each pair of measurements. Cohen's $\kappa$ coefficient was calculated to measure the agreement between the first and the second FIT. Statistical analysis was performed using PASW Statistics 18, Release Version 18.0.0 (SPSS, Inc., 2009, Chicago, IL, USA) and GraphPad Prism Version 4.00 (GraphPad Software, San Diego, CA, USA).

\section{Results}

\section{Analytical evaluation}

\section{Analytical imprecision}

The within-run imprecision CVs of the low control (mean \pm SD) $(14 \pm 1 \mu \mathrm{g} \mathrm{Hb} / \mathrm{g}$ faeces), high control (49 $\pm 1 \mu \mathrm{g} \mathrm{Hb} / \mathrm{g}$ faeces), haemoglobin-spiked buffers (29 $\pm 2 \mu \mathrm{g} \mathrm{Hb} / \mathrm{g}$ faeces; $96 \pm 4 \mu \mathrm{g} \mathrm{Hb} / \mathrm{g}$ faeces) and $\mathrm{f}-\mathrm{Hb}$ patient samples $(18 \pm 1 \mu \mathrm{g} \mathrm{Hb} / \mathrm{g}$ faeces; $100 \pm 3 \mu \mathrm{g} \mathrm{Hb} / \mathrm{g}$ faeces) ranged from $1.7 \%$ to $5.1 \%$. Between-run imprecision CVs of the low control (mean \pm SD) $(14 \pm 1 \mu \mathrm{g} \mathrm{Hb} / \mathrm{g}$ faeces) and high control ( $51 \pm 2 \mu \mathrm{g} \mathrm{Hb} / \mathrm{g}$ faeces) ranged from $3.8 \%$ to $6.2 \%$.

\section{Linearity}

Mean linearity was $101.1 \%$ for all dilutions (minimum $84.5 \%$, maximum $108.1 \%$ ), with an SD of $6.7 \%$ (Figure 1).

\section{Carry over}

The means and SDs of $\mathrm{f}-\mathrm{Hb}$ concentrations after low and high concentration samples $(7650 \mu \mathrm{g} \mathrm{Hb} / \mathrm{g}$ faeces) were $22 \pm 2 \mu \mathrm{g} \mathrm{Hb} / \mathrm{g}$ faeces and $23 \pm 1 \mu \mathrm{g} \mathrm{Hb} / \mathrm{g}$ faeces, respectively. The maximum deviation was defined as twice the SD of the first five low measurements; therefore, the intraassay carry over met the requirements.

\section{Test stability}

The decay of concentration (mean $\pm \mathrm{SD}$ ) that occurred each day the samples were stored at room temperature $\left(24^{\circ} \mathrm{C} \pm 2{ }^{\circ} \mathrm{C}\right)$ was significantly higher than when they were refrigerated $\left(6^{\circ} \mathrm{C} \pm 2{ }^{\circ} \mathrm{C}\right)(\mathrm{p}<0.05)$. The decay per day, over 20 days, at room temperature ranged from $1.4 \%$ to $11 \%$ $(2.3 \% \pm 1.2 \%)$ and when refrigerated ranged from $0.2 \%$ to $0.5 \%(0.4 \% \pm 0.3 \%)$ per day.

\section{Clinical performance}

\section{Patient and colonoscopy results}

Of the 487 patients, 71 showed ACRN on colonoscopy (14.6\%; 12 CRC and $59 \mathrm{AA})$. NAA was found in 93 patients

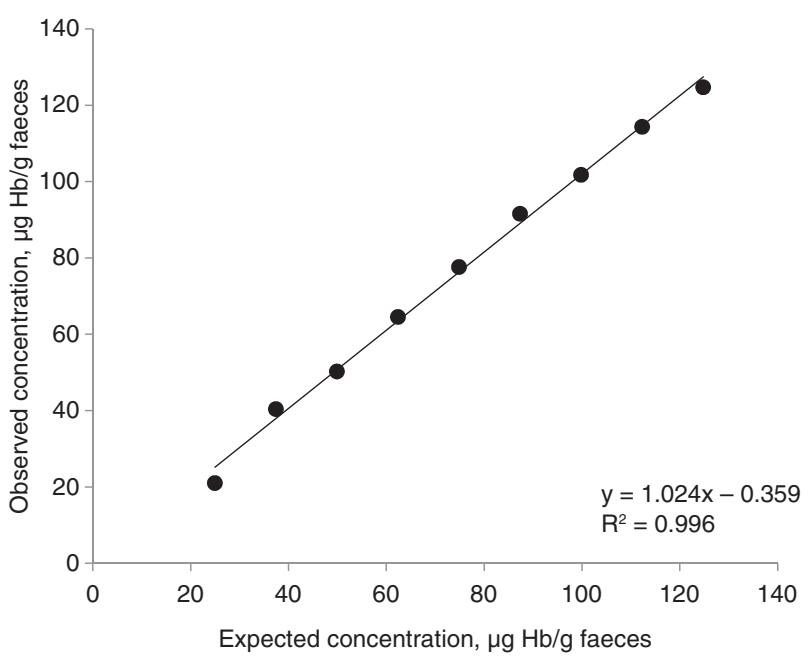

Figure 1: Linear regression of expected and observed dilution steps. 
(19.1\%), and other lesions, such as hyperplastic or inflammatory polyps (28), diverticular disease (114), haemorrhoids (149), angiodysplasia (7), inflammatory bowel disease (8) and minor irrelevant lesions (6), were found alone or in combination in 230 patients (47.2\%). Finally, there were no colonoscopy findings for 93 individuals $(19.1 \%)$.

\section{f-Hb concentrations}

For the entire population undergoing colonoscopy, the median and interquartile range (IQR) of the $\mathrm{f}-\mathrm{Hb}$ measurements for each of the analysed samples were 2 and 2-5 $\mu \mathrm{g} \mathrm{Hb} / \mathrm{g}$ faeces, respectively. The $\mathrm{f}-\mathrm{Hb}$ results according to colonoscopy and pathology diagnosis are presented in Table 1. The $\mathrm{f}-\mathrm{Hb}$ concentrations for patients with ACRN $(\mathrm{CRC}+\mathrm{AA})$ were significantly higher than those with a normal colonoscopy examination (Figure 2). The results above 10, 20, 40 and $60 \mu \mathrm{g} \mathrm{Hb} / \mathrm{g}$ faeces were $19.6 \%, 15.8 \%, 11.5 \%$ and $10 \%$, respectively.

\section{Sensitivity, specificity and predictive values for different colonoscopy findings, including ACRN}

Figure 3 shows the ROC curve for CRC and ACRN based on the FIT results for each participant. We measured the sensitivity and specificity of the FIT results at various haemoglobin cutoffs (Table 2). At a $10 \mu \mathrm{g} \mathrm{Hb} / \mathrm{g}$ faeces cutoff, the sensitivity and specificity for detecting ACRN were 46.5\% (95\% CI, 38.1\%-55\%) and 85\% (95\% CI, 82.3\%-87.3\%), respectively. At $30 \mu \mathrm{g} \mathrm{Hb} / \mathrm{g}$ faeces cutoff, the sensitivity and specificity for detecting ACRN were 33.8\% (95\% CI, $26.2 \%-42.3 \%$ ) and $91 \%$ (95\% CI, 88.8\%-92.8\%), respectively. When a $10 \mu \mathrm{g} \mathrm{Hb} / \mathrm{g}$ faeces cutoff was used, sensitivity increased by $35 \%$ and specificity decreased by $7 \%$

Table 1: $\mu \mathrm{g} \mathrm{Hb} / \mathrm{g}$ faeces concentration of all samples according to colonoscopy and pathology diagnosis.

\begin{tabular}{lrrrr}
\hline Diagnosis & No. of samples & Median & IQR & p-Value \\
\hline CRC & 24 & 637 & $101-1034$ & $<0.001$ \\
CRC +AA & 142 & 8 & $2-93$ & $<0.001$ \\
Adenomas & & & & \\
AA & 118 & 3 & $2-25$ & $<0.001$ \\
NAA & 183 & 2 & $2-11$ & $<0.001$ \\
Other & 456 & 2 & $2-4$ & 0.002 \\
Normal & 186 & 2 & $2-2$ & \\
\hline
\end{tabular}

CRC, colorectal cancer; AA, advanced adenoma; NAA, non-advanced adenoma; IQR, interquartile range. Concentrations $\leq 2 \mu \mathrm{g} \mathrm{Hb} / \mathrm{g}$ faeces might be below the limit of detection. ${ }^{\text {a Significance in }}$ relation to normal group. compared with a $30 \mu \mathrm{g} \mathrm{Hb} / \mathrm{g}$ faeces cutoff. The sensitivity for detecting CRC was considerably higher than that for detecting clinical ACRN (Table 2). In the studied group, the PPV for detecting CRC and ACRN at cutoffs between 10 and $60 \mu \mathrm{g} \mathrm{Hb} / \mathrm{g}$ faeces ranged from $11.6 \%$ to $20.6 \%$ and from $34.7 \%$ to $42.3 \%$, respectively, and the NPV for ACRN ranged from $90.2 \%$ to $88.4 \%$. Table 2 also includes the sensitivity and specificity of FIT at various f-Hb cutoffs for different colonoscopy findings. In the studied group, the sensitivity for detecting all types of colorectal lesions between cutoffs of 10 and $60 \mu \mathrm{g} \mathrm{Hb} / \mathrm{g}$ faeces ranged from $11.9 \%$ to $23 \%$ and the specificity ranged from $94.6 \%$ to $97.8 \%$.

\section{Diagnostic yield using one or two samples}

The correlation coefficients of the first and the second FITs were 0.46 . The $\kappa$ coefficient at different cutoff values (Table 3) showed a substantial agreement between the first and the second FITs. We measured f-Hb of each of two consecutive faecal samples but considered them to represent one test, to which we assigned the mean and higher result of the two FITs. Figure 4 shows the ROC curves for ACRN based on the first, mean and higher FIT measurements for each participant. No statistical differences were observed among these measurements. Table 3 shows the sensitivity and specificity of the first, second, higher and mean FIT results for ACRN at different cutoff values, as well as discrepancies between the first and the second sample and the $\kappa$ coefficient between both samples.

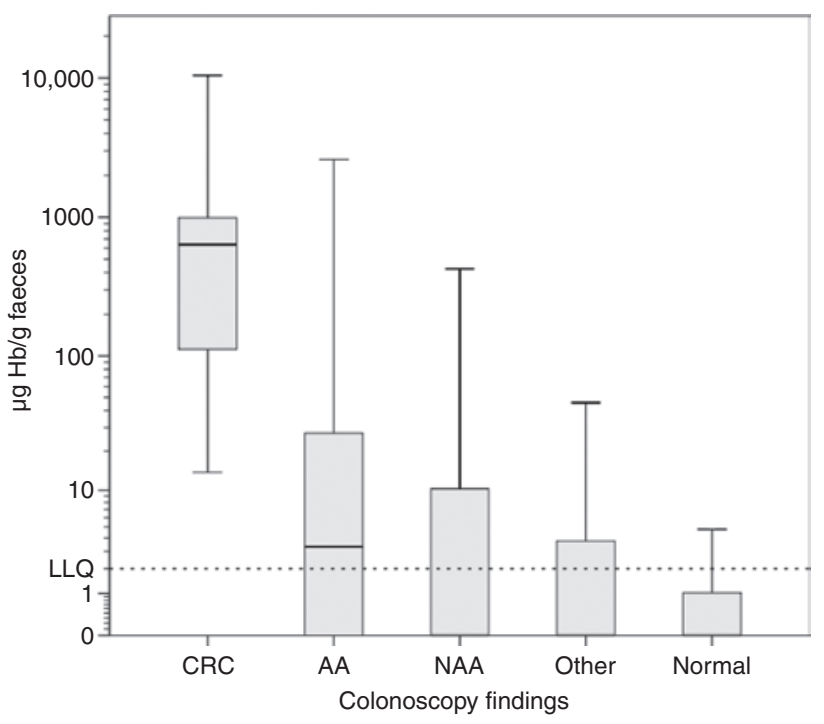

Figure 2: Box plot of $\mathrm{f}-\mathrm{Hb}$ concentration according to colonoscopy and pathology diagnosis.

CRC, colorectal cancer; AA, advanced adenoma; NAA, non-advanced adenoma; LLQ, lower limit of quantification. 
A

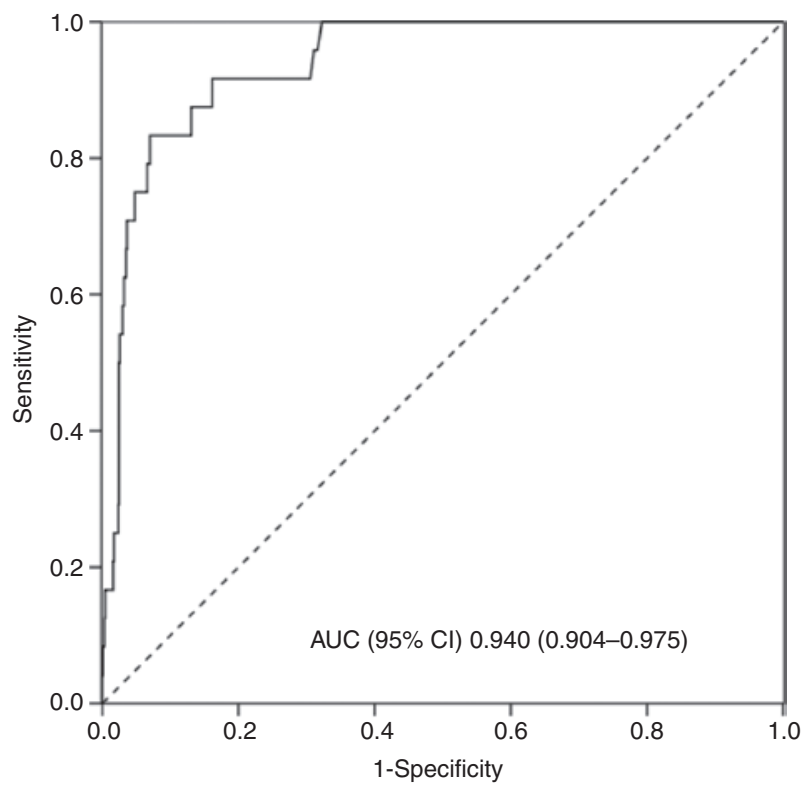

B

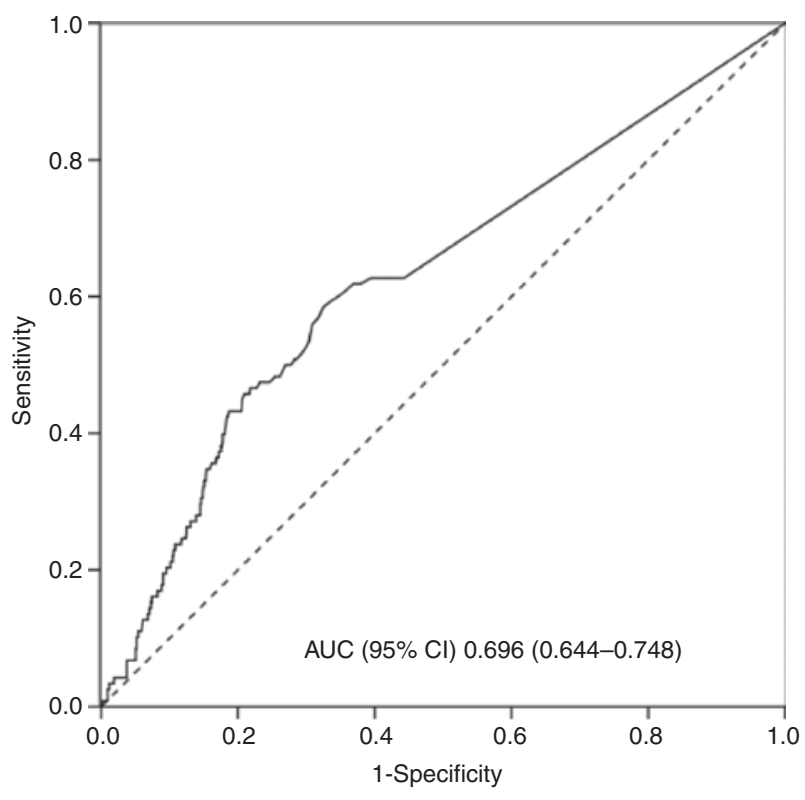

Figure 3: Receiver operating characteristic (ROC) curve of $\mathrm{f}-\mathrm{Hb}$ concentration from all samples for the identification of CRC $(A)$ and ACRN (B).

ACRN, advanced colorectal neoplasia; CRC, colorectal cancer; AUC $(95 \% \mathrm{Cl})$, area under the curve $(95 \% \mathrm{Cl})$.

\section{Discussion}

To our knowledge, this is the first study to report detailed analytical and clinical data using the SENTiFIT ${ }^{\circledR} 270$ analyser (Sentinel Diagnostics, distributed in Spain by Sysmex España, S.L.U.). This colonoscopy-controlled study permitted a detailed evaluation of an automated desktop instrument for quantitative immunochemical determination of $\mathrm{f}-\mathrm{Hb}$. The evaluation included studies of imprecision, linearity of dilution, carry over and test stability as well as a clinical study to assess the diagnostic yield.

The analytical imprecision was below $6.2 \%$. Furthermore, the effects of carry over were not detected below $7650 \mu \mathrm{g} \mathrm{Hb} / \mathrm{g}$ faeces. In a hypothetical situation in which a sample with a haemoglobin concentration higher than $7650 \mu \mathrm{g} \mathrm{Hb} / \mathrm{g}$ faeces was followed by a sample with a haemoglobin concentration near the decision cutoff, reanalysis of the latter sample would need to be considered to avoid haemoglobin contamination. However, this situation is very rare $(0.4 \%$ of the samples of the present study) because few samples have such high $\mathrm{f}-\mathrm{Hb}$ and even fewer are followed by a sample near the decision cutoff. Haemoglobin stability was evaluated at different temperatures. Samples stored in a refrigerated environment showed slight decay $(0.2 \%-0.5 \%$ per day) compared with those stored at room temperature (1.4\%-11\% per day).

In a mixed group of individuals, the sensitivity and specificity for ACRN at cutoffs between 10 and $60 \mu \mathrm{g} \mathrm{Hb} / \mathrm{g}$ faeces ranged from $28.9 \%$ (95\% CI, $21.7 \%-37.2 \%$ ) to $46.5 \%$ (95\% CI, 38.1\%-55\%) and from 85\% (95\% CI, 82.3\%$87.3 \%$ ) to $93.2 \%$ (95\% CI, $91.2 \%-94.8 \%$ ), respectively. It is important to note that the high specificity and NPV (90\%) helps rule out the presence of ACRN, which is a relevant issue in symptomatic patients. The specificity of all types of colorectal lesions at cutoffs between 10 and $60 \mu \mathrm{g} \mathrm{Hb} / \mathrm{g}$ faeces is very high $(94.6 \%-97.8 \%)$, as is the PPV for detecting colorectal lesions (95.9\%-94.7\%). However, sensitivity and NPV for all detected lesions are very low, ranging from $11.9 \%$ to $23 \%$ and from $20.9 \%$ to $22.7 \%$, respectively. This ensures detection of colorectal pathology but does not rule out minor findings such as NAA or other minor lesions. It is important because when $\mathrm{f}-\mathrm{Hb}$ is below an established cutoff, severe lesions can be ruled out and only some minor lesions may be overlooked.

Due to the study's characteristics, all patients were symptomatic or under surveillance, and therefore the positivity rate at different cutoffs was higher than in average-risk populations [27, 28]. Thus, further studies are necessary. The poor correlation between the first and the second samples can probably be ascribed to the reproduction of daily variations in blood loss, heterogeneous blood distribution inside faeces and the inherent characteristics of the specimen collection devices. Otherwise, the $\kappa$ coefficients and the discrepancies between the first and the second FITs at different cutoff values showed a substantial agreement and a proportion of discrepancies below $7 \%$.

This study confirmed that using a $40 \mu \mathrm{g} \mathrm{Hb} / \mathrm{g}$ faeces cutoff permits the detection of most CRCs (83.3\%) and 


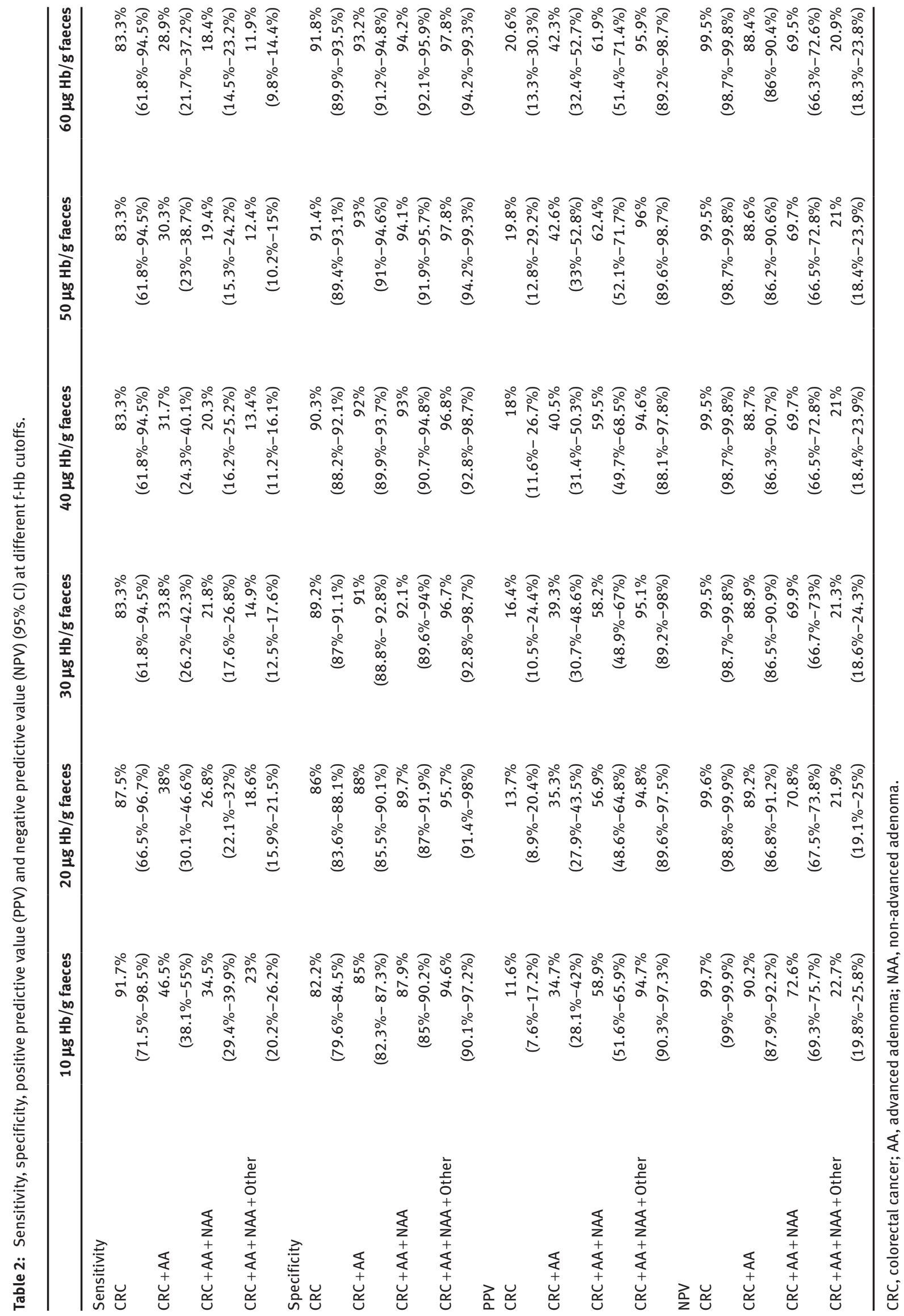




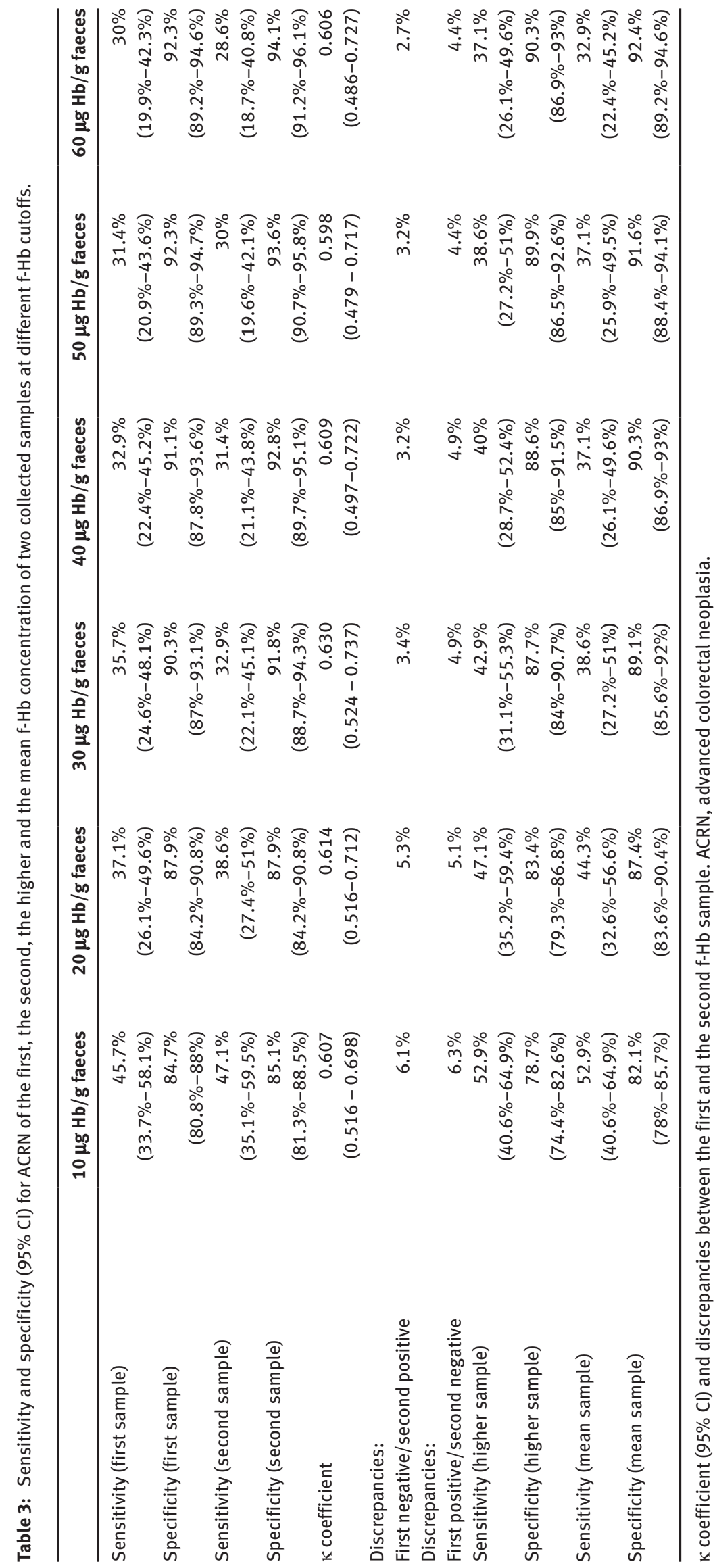




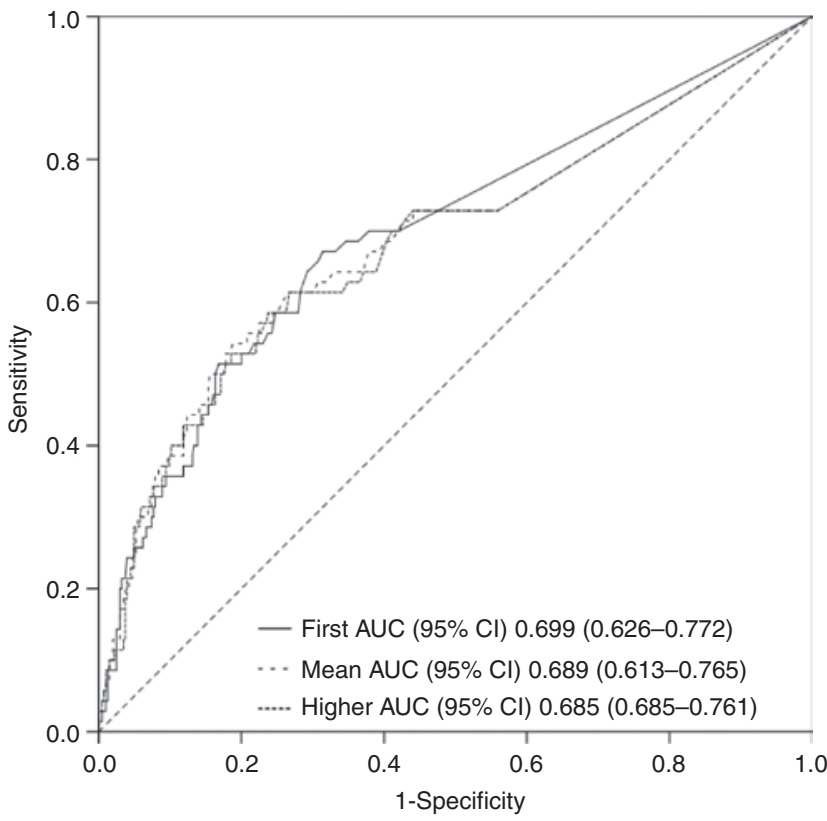

Figure 4: Receiver operating characteristic (ROC) curve of the first, the mean and the higher $\mathrm{f}-\mathrm{Hb}$ concentration of two collected samples for the identification of ACRN.

ACRN, advanced colorectal neoplasia; AUC $(95 \% \mathrm{Cl})$, area under the curve $(95 \% \mathrm{Cl})$.

$21.2 \%$ of AAs, resulting in a combined sensitivity of 31.7\% and a specificity of $92 \%$. By using two samples for each patient and choosing the highest result, the sensitivity for ACRN increases to $40 \%$, resulting in a specificity of $88.6 \%$, while on the other hand a similar diagnostic yield is obtained using only one sample and decreasing the cutoff. Moreover, when one sample and a $10 \mu \mathrm{g} \mathrm{Hb} / \mathrm{g}$ faeces cutoff are used, it is possible to rule out the majority of malignant lesions, missing two CRCs out of 24, obtaining a very high NPV (99.7\%), a characteristic observed for all $\mathrm{f}-\mathrm{Hb}$ concentrations and even at a $60 \mu \mathrm{g} \mathrm{Hb} / \mathrm{g}$ faeces cutoff, missing four CRCs out of 24 , maintaining a high NPV (99.5\%). These results can help make decisions not only related to the performance and prioritisation of colonoscopies for symptomatic patients but even ruling out malignancy in patients with low $\mathrm{f}-\mathrm{Hb}$ concentrations. Additionally, they are consistent with results from a screening set and other studies that used immunochemical tests to screen larger populations [5, 6, 29-35].

\section{Conclusions}

In conclusion, the current study provides useful data regarding the potential application of an automated FIT to CRC screening and diagnosis of symptomatic patients. The compact, fully automated immunochemistry analyser, which evaluated $\mathrm{f}-\mathrm{Hb}$ demonstrated adequate analytical and clinical performance. The test used in the current study is easy to perform, and the results are independent of the operator's experience. We have demonstrated that the SENTiFIT assay (Sentinel Diagnostics, Italy; Sysmex, Spain) is a specific and accurate test for detecting ACRN in symptomatic patients and those undergoing surveillance.

Author contributions: All the authors have accepted responsibility for the entire content of this submitted manuscript and approved submission.

Research funding: None declared.

Employment or leadership: None declared.

Honorarium: None declared.

Competing interests: The funding organization(s) played no role in the study design; in the collection, analysis, and interpretation of data; in the writing of the report; or in the decision to submit the report for publication.

\section{References}

1. Brenner $\mathrm{H}$, Haug $\mathrm{U}$, Hundt S. Sex differences in performance of fecal occult blood testing. Am J Gastroenterol 2010;105:2457-64.

2. Hol L, Wilschut JA, van Ballegooijen M, van Vuuren AJ, van d V, Reijerink JC, et al. Screening for colorectal cancer: random comparison of guaiac and immunochemical faecal occult blood testing at different cut-off levels. Br J Cancer 2009;100:1103-10.

3. Parra-Blanco A, Gimeno-Garcia AZ, Quintero E, Nicolas D, Moreno SG, Jimenez A, et al. Diagnostic accuracy of immunochemical versus guaiac faecal occult blood tests for colorectal cancer screening. J Gastroenterol 2010;45:703-12.

4. Fraser CG, Halloran SP, Allison JE, Young GP. Making colorectal cancer screening fitter for purpose with quantitative faecal immunochemical tests for haemoglobin (FIT). Clin Chem Lab Med 2013;51:2065-7.

5. Auge JM, Fraser CG, Rodriguez C, Roset A, Lopez-Ceron M, Grau J, et al. Clinical utility of one versus two faecal immunochemical test samples in the detection of advanced colorectal neoplasia in symptomatic patients. Clin Chem Lab Med 2016;54:125-32.

6. Cubiella J, Salve M, Diaz-Ondina M, Vega P, Alves MT, Iglesias F, et al. Diagnostic accuracy of the faecal immunochemical test for colorectal cancer in symptomatic patients: comparison with NICE and SIGN referral criteria. Colorectal Dis 2014;16:0273-82.

7. Godber IM, Todd LM, Fraser CG, MacDonald LR, Younes HB. Use of a faecal immunochemical test for haemoglobin can aid in the investigation of patients with lower abdominal symptoms. Clin Chem Lab Med 2016;54:595-602.

8. McDonald PJ, Digby J, Innes C, Strachan JA, Carey FA, Steele RJ, et al. Low faecal haemoglobin concentration potentially rules out significant colorectal disease. Colorectal Dis 2013;15:e151-9.

9. Mowat C, Digby J, Strachan JA, Wilson R, Carey FA, Fraser CG, et al. Faecal haemoglobin and faecal calprotectin as indicators of bowel disease in patients presenting to primary care with bowel symptoms. Gut 2016;65:1463-9. 
10. Rodriguez-Alonso L, Rodriguez-Moranta F, Ruiz-Cerulla A, Lobaton T, Arajol C, Binefa G, et al. An urgent referral strategy for symptomatic patients with suspected colorectal cancer based on a quantitative immunochemical faecal occult blood test. Dig Liver Dis 2015;47:797-804.

11. Widlak MM, Thomas CL, Thomas MG, Tomkins C, Smith S, O'Connell N, et al. Diagnostic accuracy of faecal biomarkers in detecting colorectal cancer and adenoma in symptomatic patients. Aliment Pharmacol Ther 2017;45:354-63.

12. Hol L, van Leerdam ME, van Ballegooijen M, van Vuuren AJ, van Dekken H, Reijerink JC, et al. Screening for colorectal cancer: randomised trial comparing guaiac-based and immunochemical faecal occult blood testing and flexible sigmoidoscopy. Gut 2010;59:62-8.

13. Park DI, Ryu S, Kim YH, Lee SH, Lee CK, Eun CS, et al. Comparison of guaiac-based and quantitative immunochemical fecal occult blood testing in a population at average risk undergoing colorectal cancer screening. Am J Gastroenterol 2010;105:2017-25.

14. van Rossum LG, van Rijn AF, van Oijen MG, Fockens P, Laheij RJ, Verbeek AL, et al. False negative fecal occult blood tests due to delayed sample return in colorectal cancer screening. Int J Cancer 2009;125:746-50.

15. van Rossum LG, van Rijn AF, Laheij RJ, van Oijen MG, Fockens $\mathrm{P}$, van Krieken HH, et al. Random comparison of guaiac and immunochemical fecal occult blood tests for colorectal cancer in a screening population. Gastroenterology 2008;135:82-90.

16. Whitlock EP, Lin JS, Liles E, Beil TL, Fu R. Screening for colorectal cancer: A targeted, updated systematic review for the US Preventive Services Task Force. Ann Intern Med 2008;149:638-58.

17. Phalguni A, Seaman H, Routh K, Halloran S, Simpson S. Tests detecting biomarkers for screening of colorectal cancer: What is on the horizon? GMS Health Technol Assess 2015;11:1-14.

18. Carroll M, Piggott C, Pearson S, Seaman H, Halloran S. Evaluation of quantitative faecal immunochemical tests for haemoglobin. Guildford, UK: Guildford Medical Device Evaluation Centre (GMEC), 2014

19. Fraser CG, Allison JE, Halloran SP, Young GP. A proposal to standardize reporting units for fecal immunochemical tests for hemoglobin. J Natl Cancer Inst 2012;104:810-4.

20. Fraser CG, Allison JE, Young GP, Halloran SP, Seaman H. A standard for faecal immunochemical tests for haemoglobin evaluation reporting (FITTER). Ann Clin Biochem 2014;51:301-2.

21. Rapi S, Rubeca T, Fraser CG. How to improve the performances of fecal immunological tests (FIT): need for standardization of the sampling and pre-analytical phases and revision of the procedures for comparison of methods. Int J Biol Markers 2015;30:e127-31.

22. Rubeca T, Cellai F, Confortini M, Fraser CG, Rapi S. Impact of preanalytical factors on fecal immunochemical tests: need for new strategies in comparison of methods. Int J Biol Markers 2015;30:e269-74.
23. Chiang TH, Chuang SL, Chen SL, Chiu HM, Yen AM, Chiu SY, et al. Difference in performance of fecal immunochemical tests with the same hemoglobin cutoff concentration in a nationwide colorectal cancer screening program. Gastroenterology 2014;147:1317-26.

24. Haeckel R. Recommendations for the application of statistical methods in the comparison of methods of clinical chemical analysis. J Clin Chem Clin Biochem 1982;20:107-10.

25. Hassan C, Quintero E, Dumonceau JM, Regula J, Brandao C, Chaussade $S$, et al. Post-polypectomy colonoscopy surveillance: European Society of Gastrointestinal Endoscopy (ESGE) guideline. Endoscopy 2013;45:842-51.

26. Sobin L, Gospodarowicz M, Wittekind C. TNM classification of malignant tumours. 7th ed. New York: Wiley-Blackwell, 2009.

27. Castiglione G, Zappa M, Grazzini G, Rubeca T, Turco P, Sani C, et al. Screening for colorectal cancer by faecal occult blood test: comparison of immunochemical tests. J Med Screen 2000;7:35-7.

28. Grazzini G, Visioli CB, Zorzi M, Ciatto S, Banovich F, Bonanomi AG, et al. Immunochemical faecal occult blood test: Number of samples and positivity cutoff. What is the best strategy for colorectal cancer screening? Br J Cancer 2009;100:259-65.

29. Allison JE, Tekawa IS, Ransom LJ, Adrain AL. A comparison of fecal occult-blood tests for colorectal-cancer screening. N Engl J Med 1996;334:155-9.

30. Auge JM, Rodriguez C, Pellise M, Bernal A, Grau J, Castells A, et al. Analytical and clinical performance of Kroma iT, a compact fully-automated immunochemistry analyzer for fecal occult hemoglobin. Anticancer Res 2013;33:5633-7.

31. Petrelli N, Michalek AM, Freedman A, Baroni M, Mink I, Rodriguez-Bigas M. Immunochemical versus guaiac occult blood stool tests: results of a community-based screening program. Surg Oncol 1994;3:27-36.

32. Robinson MH, Pye G, Thomas WM, Hardcastle JD, Mangham CM. Haemoccult screening for colorectal cancer: the effect of dietary restriction on compliance. Eur J Surg Oncol 1994;20:545-8.

33. St John DJ, Young GP, Alexeyeff MA, Deacon MC, Cuthbertson AM, Macrae FA, et al. Evaluation of new occult blood tests for detection of colorectal neoplasia. Gastroenterology 1993;104:1661-8.

34. Grobbee EJ, van der Vlugt M, van Vuuren AJ, Stroobants AK, Mundt MW, Spijker WJ, et al. A randomised comparison of two faecal immunochemical tests in population-based colorectal cancer screening. Gut 2017;66:1975-82. [Epub ahead of print].

35. Passamonti B, Malaspina M, Fraser CG, Tintori B, Carlani A, D’Angelo $\mathrm{V}$, et al. A comparative effectiveness trial of two faecal immunochemical tests for haemoglobin (FIT). Assessment of test performance and adherence in a single round of a population-based screening programme for colorectal cancer. Gut 2016. doi: 10.1136/gutjnl-2016-312716. [Epub ahead of print]. 